\title{
Caciquismo y prensa en España: las convulsas relaciones de periodistas y políticos a finales del siglo XIX. Caso del periodista malagueño Francisco de Asís García Peláez (1891-1899)
}

\author{
JUAN ANTONIO GARCIA GAIINDO
}

\section{INTRODUCCION ${ }^{1}$}

En el mes de junio de 1891 el redactor jefe y entonces director accidental del periódico malagueño DIARIO MERCANTIL, el periodista Francisco de Asís García Peláez, era condenado a la pena de reclusión, siendo internado en la Penitenciaría de Santoña en Santander, como autor del asesinato del concejal electo de la ciudad, Manuel Loring y Heredia, hermano político del entonces Ministro de la Gobernación, Francisco Silvela.

La escasa claridad de los hechos, al parecer nunca del todo demostrados, así como la personalidad de la víctima y las consecuencias e implicaciones que el caso trajo consigo, despertaron en la opinión pública española un interés inusual, fomentado por los sectores políticos, profesionales y periodísticos del país que solicitaron el indulto para el periodista malagueño. Este llegó en 1898, y con él el destierro de García Peláez, quien moriría un año más tarde en plena travesía hacia Nueva York.

Lás campañas periodísticas que Francisco García Peláez lanzó contra Joaquín Ferrer y Casanova, director de la Caja de Ahorros y Monte de Piedad y concejal silvelista en las elecciones de mayo de 1891, por la

(1) Muy bien podría ser añadido el caso del periodista malagueño Francisco de Asís García Peláez (Málaga, 1865/La Habana-Nueva York, 1899) a la abundante lista que el profesor José ALTABELLA recoge en sus -Notas para un elenco del martirologio de periodistas del siglo XIX., que publicara en 1983. En el volúmen colectivo La prensa en la revolución liberal. España, Portugal y América Latina, Ed. Universidad Complutense de Madrid, 1983, págs. 525-542. Otro periodista malagueño que merecería ingresar en ese elenco podría ser Teobaldo Nieva Aguilar (Málaga, 1834/1894), quien también sufrió la agresión física y la cárcel en el ejercicio del periodismo y en la defensa de sus ideas. Sobre Teobaldo Nieva puede consultarse la obra de Manuel MORALES MUÑOZ, Málaga, la memoria perdida: los primeros militantes obreros, Ed. Servicio de Publicaciones de la Diputación provincial de Málaga, Biblioteca Popular Malagueña, Edición de bolsillo, ri̊ 41, Málaga 1989, págs. 67-81. 
adquisición fraudulenta de acciones de la Compañía Francesa de Aguas de Torremolinos a nombre de la entidad financiera, trataron de ser silenciadas por el propio Ferrer, quien logró hacer intervenir a Manuel Loring a cambio del apoyo que éste había obtenido de sus correligionarios malagueños en las recientes elecciones municipales, entre quienes se contaba Joaquín Ferrer.

Según testimonios posteriores del periodista, fue el señor Loring el que lo abordó la noche del día 7 de junio en el Café Inglés de Málaga, obligándole a salir a la calle, e iniciando una sangrienta refriega que acabaría, sin embargo, con la muerte a tiros del alcalde. De resultas de los hechos no sólo moría el jefe de filas del silvelismo municipal, sino que desaparecería además el DIARIO MERCANTIL, periódico liberal que había fundado en 1866 Rafael García Sánchez, padre de García Peláez. Dirigía entonces el periódico su hermano Luis, que se encontraba ausente en el momento de los hechos, y sobre quien también recayó la acción de la justicia, pues también fueron confiscados sus bienes. Ello supuso la desaparición definitiva del periódico, lo que vino a profundizar aún más la crisis por la que atravesaba entonces el viejo periodismo malagueño, inmerso como estaba ya en un proceso de paulatina desaparición.

Un análisis de estos hechos nos han puesto de manifiesto, además de una mayor claridad de los sucesos, las contradicciones en que se desenvolvía el sistema canovista, dando rienda suelta a las actitudes caciquiles de la clase política, y las dificultades de los periódicos para sostener campañas críticas y reveladoras de los negocios y ocultos intereses de la oligarquía dominante.

\section{EL DIARIO MERCANTIL Y LA FAMILIA GARCIA PELAEZ}

Francisco de Asís García Peláez contaba 25 años cuando se produce el luctuoso suceso que hubo de trastocar para siempre su vida. Había nacido en Málaga el día 24 de diciembre de 1865 , en el seno de una familia burguesa vinculada por partida triple al comercio, a la política y al periodismo. Su padre, Rafael García Sánchez, había sido un prohombre del periodismo local, maestro de periodistas y persona muy respetada en el oficio, quien había fundado en 1866 el DIARIO MERCANTIL. Este periódico, de carácter liberal fusionista, compartía con EL AVISADOR MALAGUEÑO, EL CORREO DE ANDALUCIA y LAS NO'TICIAS -los más importantes diarios de la ciudad- la representación del viejo periodismo malagueño, aún dominante pero que estaba a punto de entrar en los prolegómenos de su crisis definitiva; a la que había venido a contribuir la reciente aparición de un nuevo diario de diferente factura y nuevos bríos, LA UNION MERCANTIL.

A la muerte de Rafael García Sánchez, que fue muy sentida en los círculos periodísticos de la ciudad, como pudieron reflejar las numerosas 
muestras de condolencia que recogieron los periódicos locales, sus hijos Luis y Francisco de Asís se hicieron cargo de la empresa familiar, pasando el primero de ellos a ocupar la dirección del diario, y el segundo la jefatura de redacción. No obstante, la propiedad del periódico sería compartida además con el resto de los hijos de García Sánchez: 'con Manuel, el mayor de todos ellos, quien desempeñaba la dirección de EL CORREO DE ANDALUCIA, y con la menor de todos y única hermana ${ }^{2}$.

Desde muy pronto, el joven Francisco de Asís, que había crecido en un ambiente propicio, empezará a dejar muestra de sus inquietudes literarias. Nos cuenta Narciso Díaz de Escovar, con quien nuestro personaje mantuvo, en los años que siguieron al hecho que nos ocupa, una asidua relacion espistolar, que era muy niño cuando ya redactaba (en) el DIARIO MERCANTIL, dirigiendo más tarde su hoja literaria $x^{3}$. Era obvio que tenía todas las facilidades para ello. A pesar de lo impreciso de la referencia cronológica que nos proporciona Díaz de Escovar, resulta común esa precocidad en muchos periodistas de la época, en particular entre aquellos que vivieron durante su infancia y adolescencia en un medio adecuado. Aquellas dotes de escritor le fueron premiadas en varias ocasiones: :En el Certamen que en las fiestas de la Reconquista [1887] organizó el Círculo de Obreros Católicos obtuvo un primer premio por una bella poesía. Poco después fue premiado en otro concurso una obra relativa a la Historia de Málaga. También fue laureado en un Certamen del Centro Militar. ${ }^{4}$. Añade nuestro cronista que Francisco de Asís llegó además a fundar un semanario literarios.

En definitiva, cuando García Peláez inicia sus campañas contra la Caja de Ahorros es, pese a su juventud, un avezado periodista, a quien también comenta Díaz de Escovar- caracterizaba la energía de sus polémicas. Será precisamente este carácter apasionado del periodista el que le acabe jugando la peor pasada. Políticos y periodistas estuvieron de acuerdo en considerar como excesivamente virulento el tono empleado por García Peláez en el ejemplar del DIARIO MERCANTIL del día 7 de junio,

(2) La sede del periódico se encontraba por entonces en la calle Molinillo del Aceite, $n^{\circ} 12$, bajo.

(3) DIAZ DE ESCOVAR, Narciso, Notas manuscritas: Biografia de Francisco de Asís García Peláez. A.D.E., Caja 166.

(4) Ibíd.

(5) La tragedia personal que supuso para García Peláez la muerte de Manuel Loring marcaría además su inquietud literaria posterior. Fruto de los años de encarcelamiento fueron sus obras .Del otro mundo. (Málaga, 1892) y .Deshonra por gratitud. (drama en tres actos, s.f.), en las que el tema central es siempre su inocencia; convertidas así; con la obsesión y el convencimiento de quien no se reconoce culpable, en parte de su defensa ante la opinión pública; alegato sobre el que volverá, una vez en libertad, en el manifiesto que publica en Lisboa en 1898 titulado Al pueblo de Málaga, y al que nos referiremos más adelante. Víd. A.D.E., Caja 166. 
en el que contestaba a las cartas que los accionistas y miembros de la junta directiva de la Caja habían enviado a Ferrer y Casanova en apoyo a su gestión al frente de la entidad. Tras el incidente en que perdería la vida el concejal electo, EL AVISADOR MALAGUEÑO y especialmente LA UNION MERCANTIL se manifestaron contrarios a la forma en que el periodista había llevado la campaña. Aquella postura de la prensa inclinó aún más la balanza en contra del periodista, justo cuando todas las opiniones le señalaban sin paliativos como culpable, y únicamente contribuyó al ocultamiento de las circunstancias que rodearían a los hechos.

Los periódicos malagueños, tanto los progresistas como los conservadores, no sólo no se mantuvieron en ese momento al margen de la cuestión, sino que se alinearon con la postura aparentemente mayoritaria de la sociedad malagueña que veía en el periodista a un vulgar asesino. El día 9 de junio el diario que dirigía Fernández y García saldría a la calle proponiendo la mesura en los juicios periodísticos, situándose así de manera intencionada en el espacio de equilibrio y moderación que la nueva prensa independiente quería presentar $r^{6}$. Lo mismo hizo en días sucesivos ${ }^{7}$, pues era el momento apropiado para que periódicos de la factura de LA UNION MERCANTIL ganaran adeptos, ya que según el diario independiente la prensa de partido siempre defendería posiciones extremas, corriéndose el peligro de llegar a situaciones como la recientemente ocurrida. En suma, casi todos los periódicos locales quisieron ver en el incidente a un único culpable, que llevado por la vehemencia de su carácter había acabado con la vida del futuro alcalde de la ciudad ${ }^{8}$.

\section{LOS HECHOS}

En mayo de 1891, según testimonios del propio periodista, García Peláez recibió la visita de un grupo de clientes de la Caja de Ahorros y

(6) LA UNION MERCANTIL, 9 de Junio de 1891, pág. 1, ¿¿Servirá de enseñanza?: •(..) La muerte del señor $\mathrm{D}$. Manuel Loring, con motivo de incidentes relacionados con la polémica de un periódico, viene a demostrar una vez más la necesidad imperiosa de que no se emplee la violencia del lenguaje en la crítica o censura de los actos, procurando que las elucubraciones destinadas al público más se distingan por la imparcialidad que por el apasionamiento (...) Los periódicos no pueden ni deben ser carteles de desafío (...) El lenguaje debe ser mesurado, cortés, circunspecto (...) De otro modo hace la prensa algo más que apartarse de su misión; se convierte en un peligro inmenso para la sociedad.

(7) Víd. LA UNION MERCANTIL, 11 de Junio de 1891, pág. 1, .Lo que debe ser la prensa*; 15 de Junio de 1891, págs. 2-3, .La cuestión de la prensa.; y 18 de Junio de 1891, pág. 1, -La cuestión de la prensa (continuación).

(8) Cfr. LA UNION MERCANTIL y EL AVISADOR MALAGUEÑ̃ de los días siguientes al hecho, que se conservan en el A.D.E. Así como EL COMBATE, de fecha 8 de Noviembre de 1891, que rememora la figura de Loring, y se conserva en el A.M.M., sig. 2.

(9) Cfr. LA UNION MERCANTIL, 8 y 9 de Junio de 1891; y EL AVISADOR MALAGUEÑo, 9 de Junio de 1891. 
Monte de Piedad (de rmodestos industriales• y thonrados obreros•, como él mismo los describe), que le refirieron la malversación que de sus ahorros venía haciendo la Dirección de la entidad. El día 27 de aquel mes, García Peláez publicó el primero de los artículos sobre la citada entidad financiera, campaña que duraría hasta el día 7 de junio. En la tarde del día 27 recibió otra visita, la del corredor de comercio y director de la Caja de Ahorros y Monte de Piedad de Málaga, Joaquín Ferrer y Casanova, cargo que 'ocupaba desde 1888, quien pretendió convencerlo de la legalidad de las operaciones que se estaban realizando. Pese a que no logró hacerlo, el día 30 de mayo insertó el DIARIO MERCANTIL un comunicado de Ferrer en el que se repetían los mismos argumentos que éste había expuesto a García Peláez ${ }^{10}$.

Sin embargo, el DIARIO MERCANTIL siguió tratando el asunto los días -29 y 31 de mayo, 2, 4 y 6 de junio; "probé -prosigue el periodistaque hubo malversación de caudales; determiné el despojo de los infelices imponentes en la Caja de Ahorros; definí responsabilidades, y pedí, con todos los respetos que la entidad me merecía y con las citas legales que mi petición amparaban, la intervención del Juzgado, del Fiscal de S.M. en el asunto; su inspección de las ilegales operaciones realizadas por el Director de la Caja de Ahorros y su acción legalísima en severa exigencia de las debidas responsabilidades. ${ }^{11}$.

Según explican los hermanos de García Peláez, Joaquín Ferrer había adquirido en nombre de la Sociedad Monte de Piedad una importante suma de acciones de la Compañía Francesa de Aguas de Torremolinos que abastecía a la ciudad de Málaga; sin embargo, según el reglamento por el que se regía la citada sociedad financiera no debían rrealizarse operaciones que excedan a la suma de diez mil pesetas y éstas (en caso de verificarse) sea con la garantía de las firmas de tres respetables casas

(10) -Le di publicidad, porque a ello me indujo, en primer término, la lealtad en que inspiraba mi campaña, y también porque el comunicado aludido era la prueba más clara, la confesión más explícita de la mala fe con que el Director de la Caja de Ahorros defendía su desdichada gestión. Sí; porque en apoyo de la misma citaba Ferrer algunos artículos del Reglamento de la Caja de Ahorros y Monte de Piedad; pero mutilándolos de tal modo en lo que no convenía con su acción, y adicionándoles tan calculadamente lo que pudiera justificarle, que el solo hecho de publicar yo a continuación los artículos citados, pero con toda su exactitud, con toda su verdad, bastó para llevar al ánimo de todos el convencimiento de la razón en que yo me inspiraba y de la sinrazón en que Ferrer se debatía. GARCIA PELAEZ, Francisco de Asís, Al pueblo de Málaga, Lisboa 1898. A.D.E., Caja 172.

(11) Ibíd. Desconocemos la existencia de fondos hemerográficos del DIARIO MERCANTIL de estas fechas después de haber consultado la práctica totalidad de los Archivos y Hemerotecas españoles que conservan prensa malagueña, lo que nos impide conocer directamente el contenido de la campaña emprendida por García Peláez. 
comerciales. ${ }^{12}$. Ni siquiera el director estaba autorizado para llevar a cabo tales operaciones, y mucho menos por la cantidad que Ferrer pretendía, que ascendía a cincuenta mil pesetas, por lo que el registro general de aguas denegó al director del Monte de Piedad la inscripción de las mencionadas acciones a nombre de la entidad ${ }^{13}$.

Como respuesta a la campaña iniciada por el DIARIO MERCANTIL contra Ferrer y Casanova, los accionistas y miembros de la Junta de gobierno del Monte de Piedad de Málaga manifestaron públicamente su apoyo y su solidaridad con el director de la Caja, mediante dos cartas dirigidas a éste, que el propio Ferrer se ocupó personalmente de insertar en otros periódicos.

Los miembros de la Junta de gobierno de la Caja firmantes de la primera carta eran: L.A. Bolín, G. Rein, Eduardo Loring, B. Ghiara, José Molina, Vicente Martínez Montes, Juan N. Blasco Barroso, Quirico López y Sebastián Souvirón. Por su parte, los accionistas que firmaban la otra de las cartas, en la que mostraban la total aceptación del contenido de la primera, fueron: Jorge Loring, José Gálvez, Enrique Petersen, Scholz Hermanos, Federico Gros, Juan Clemens, Guillermo Bolín, Pedro Antonio de Orueta, y Delius Hermanos y Compañía. Los acuerdos adoptados por los firmantes de ambas cartas fueron los que siguen: $11^{2}$.- Aceptar y tener por nuestros los actos todos de usted en el desempeño de sus funciones de Director (...) $2^{\circ}$.- Rogar a usted con el mayor encarecimiento que, dando al olvido lo que al olvido es de dar, ni siquiera imagine declinar la honrosa distinción, que merece, de dirigir el citado establecimiento. $3^{\circ}$.Suplicar a usted con no menor interés que cuide de insertar esta carta en los periódicos de mayor circulación de esta ciudad ${ }^{14}$.

Este abierto apoyo a la gestión de Ferrer y Casanova llevó al DIARIO MERCANTIL a arreciar sus denuncias de manera simultánea contra los firmantes de la citada carta, contra la propia institución y contra su director, que fueron ya especialmente intensas en el número del día 7 de junio de 1891, día de autos.

\section{El incidente}

A primeras horas de aquella noche se encontraban cenando en el Café Inglés, sito en la Plaza del Siglo, Manuel Loring, José Miró y Sixto, juez municipal y entonces interino de primera instancia, y Luis Aparici,

(12) La opinión priblica y el indulto al periodista D. Francisco de Asís García Peláez, Madrid 1896, pág. 3. A.D.E., Caja 166.

(13) Ibid.

(14) El contenido íntegro de ambas cartas en GARCIA PELAEZ, Francisco de A., Al pueblo de Málaga, op. cit. 
cuando entró en el establecimiento, adonde acudía con regularidad, Francisco de Asís García Peláez acompañado de Eduardo Lustonó. La presencia del periodista parece ser que recordó al político las denuncias que aquel mismo día se vertían en su periódico contra los miembros de la Caja, con los que Loring mantenía vínculos políticos e incluso de parentesco. A petición de éste salieron ambos del café, adentrándose los dos en el callejón contiguo al establecimiento que se abría también a la misma plaza. Después de una breve discusión, que según las primeras declaraciones no tuvo testigos directos, se oyeron tres disparos, tras los cuales apareció el periodista herido en la cabeza, el cual se dirigió de nuevo al café atravesándolo y dirigiéndose a la cocina para salir por la puerta que daba al Cañuelo. Quienes acudieron a socorrer a Manuel Loring lo encontraron herido de muerte por dos disparos de bala en el pecho.

Según datos de LA UNION MERCANTIL, periódico que desplazó de inmediato a un reporter al lugar de los hechos, el concejal ya moribundo estuvo asistido por Luis Aparici y el escribano José Ponce de León, así como por el sereno Francisco Dueñas, el guardacalle Juan Alba y el portero del Ayuntamiento Joaquín Jurado, quienes lo condujeron a la casa de socorro de calle San Agustín, donde murió. Mientras tanto el juez José Miró, quien también cenaba con la víctima, intentó inútilmente detener al agresor ${ }^{15}$.

La expectación que despertó el hecho atrajo a un inmenso gentío que se agolpó por los alrededores de la Plaza del Siglo, Plaza del Carbón, Plaza de Uncibay y Calle San Agustín. Asimismo numerosas personalidades de la vida local acudieron rápidamente al lugar de los hechos y a la Casa de Socorro donde en los primeros momentos se encontraba el cadáver. El Alcalde de la ciudad; el Presidente de la Audiencia; el Secretario, señor Sola; el Delegado de Hacienda; los Diputados a Cortes, señores Dávila y Gómez Pizarro, etc., acudieron a la Casa de Socorro, así como numerosos médicos que se personaron para asistir a la víctima ${ }^{16}$. Por su parte, el Deán de la Catedral, Calvente Salazar, le administró la Extremaunción poco antes de morir.

Con la misma rapidez que se había desarrollado el incidente, tuvieron lugar las primeras actuaciones judiciales. El juez de guardia, señor Rivas, el teniente fiscal, Faustino Alonso, y el escribano Sánchez Millán tomaron las primeras declaraciones a José Miró, a Luis Aparici y a una criada de Sánchez Millán que *al parecer había presenciado* los sucedido

(15) LA UNION MERCANTIL, 8 de Junio de 1891, pág. 3, .El suceso de anoche.

(16) Ibíd.: Entre los médicos se encontraban José Mamely, José Martín Navarro, Manuel Mencheca, Manuel de la Espada, Carlos Dávila, Miguel Segura, Francisco Reina, los forenses Francisco Cazorla y Juan Rafael Ramírez Pérez, y el director de la Casa de
Socorro, Baltasar de Sola. 
desde el balcón de su vivienda, situada en el callejón donde había tenido lugar el sangriento hecho. Asimismo el juzgado se hizo cargo de un ejemplar del día del DIARIO MERCANTIL.

Durante las primeras horas los rumores sobre el paradero del periodista fueron insistentes. Al mismo tiempo, se creaba en la opinión pública una imagen del periodista de peligroso criminal que fue paulatinamente en aumento; "convencidos. de que había actuado premeditadamente y de que tenía preparada su fuga, las autoridades locales solicitaron al consul francés que suspendiera la salida del vapor correo "Marechal Canrobert", "pues se sospechaba que pudiera haber huído con dirección a Gibraltar. ${ }^{17}$. Entretanto, García Peláez, también herido, se había refugiado en el número 2 de la Plaza de Uncibay, donde no tardaría en ser localizado y puesto a disposición judicial.

A las diez de la noche, el sargento Segura, jefe del puesto de la Guardia Civil, y el cabo de serenos del tercer distrito, Francisco Fernández, irrumpieron en la casa de la Plaza Uncibay donde se había ocultado el periodista, conduciéndolo posteriormente al cuartel de la Guardia Civil, de donde pasó a la cárcel ${ }^{18}$. Allí, el médico titular, Luis Gómez Díaz, le curó de cinco contusiones en la cabeza que sle habían sido causadas con un instrumento punzante; $\mathrm{y}$ a continuación el juzgado le tomaría declaración, en cuya diligencia se hallaba ocupado aún a las dos de la madruga$\mathrm{da}$, hora en que se retiró el reporter de LA UNION MERCANTIL. Sin embargo, García Peláez recuerda así aquel episodio: "En la cárcel me esperaba también un facultativo, que a las cuatro horas de ser hechas mis heridas, las curó con la posible eficacia. Quedé con toda la cabeza envueltas en algodones y vendajes, y ... comparecí ante el Juzgado... Media hora más tarde atravesaba el patio de la cárcel, y era arrojado al fondo de una inmunda cuadra donde permanecí incomunicado durante SIETE DIAS, sin lecho donde descansar y apenas sin alimento. ${ }^{19}$.

Desde las once y media de la noche se había instalado la capilla ardiente de Manuel Loring en la que poseían los Heredia en su casa de la Alameda Principal, $\mathrm{n}^{2} 28$, donde fue visitado por numerosas personas; la manifestación de duelo duró desde aquella misma noche hasta las cuatro de la tarde del día siguiente en que sería enterrado. Allí, el pintor Moreno

(17) Ibíd.

(18) Víd. el relato de Francisco Fernández, cabo de serenos del tercer distrito, y Francisco Portillo, sereno de calle Granada, sobre la captura de García Peláez, en la que ambos participaron directamente. LA UNION MERCANTIL, 9 de Junio de 1891, pág. 1, .Lo de anteanoche. La captura.

(19) GARCIA PELAEZ, Francisco de Asís, .La noche triste. (1893), en La opinión pública y el indulto del periodista Francisco de Asís García Peláez:, op. cit., pág. 12. 
Carbonero tomaría apuntes del fallecido, cuyo cadaver fue también fotografiado por los fotógrafos Oses y Gaetner ${ }^{20}$.

Parece ser que Loring había acudido al Café Inglés, a instancias de Miró, quien conocía las costumbres de García Peláez, el cual iba diariamente a cenar a dicho establecimiento sobre las siete de la tarde. ¿Por qué este interés de Loring en el asunto? Aunque Loring no había sido en ningún momento objeto de crítica por parte del DIARIO MERCANTIL, y tampoco tenía intereses directos en la Caja de Ahorros, por una parte la intervención de Ferrer, que había salido elegido concejal del Ayuntamiento en sus mismas filas, y por otra los vínculos de parentesco que mantenía con algunos de los miembros de la entidad bancaria (su suegro, Vicente Martínez Montes; y sus hermanos Jorge y Eduardo), parece que fueron motivos suficientes para impulsarle a tomar cartas en el asunto.

Ferrer quien con anterioridad a la llegada de Loring a Málaga para encabezar las listas conservadoras a las elecciones municipales había constituído una agrupación política independiente entre sectores comerciales e industriales de la ciudad, con objeto de participar en la contienda electoral, acabaría incorporándose a las filas conservadoras, pues el apoyo gubernamental con que contaba Loring le vaticinaban a este último mejores resultados. El triunfo en las elecciones garantizaban la Alcaldía a Loring, pero gracias al apoyo de los adeptos a Ferrer aquel pudo constituir su propio grupo municipal. Dado que el apoyo de Ferrer había sido importante para Manuel Loring, éste pudo sentirse deudor de él.

Loring trató de encontrarse con Luis García Peláez, a quien consideraba autor de la campaña orquestada contra Ferrer por su condición de director del diario; no sabía, sin embargo, que Luis, que también se había presentado, aunque sin éxito, a las elecciones municipales en las filas liberales, se hallaba de vacaciones desde hacía quince días en Marmolejo (Jaén), y que Francisco de Asís ocupaba interinamente la dirección, siendo el responsable de los artículos. Fue a través del mayor de los hermanos, Manuel, director de EL CORREO DE ANDALUCIA, órgano del partido conservador en Málaga, a quien Loring conocía, como supo quien era el autor de la campaña. No sin que Manuel increpara previamente a Loring sobre lo funesto de su actitud.

García Peláez, por tanto, no conocía personalmente a Loring cuando éste lo abordó en el Café Inglés. Precisamente la tarde del día siete había permanecido en su domicilio esperando a que algunos amigos de Ferrer fueran a visitarle para pedirle explicaciones por el artículo de aquel día. No podía vislumbrar lo que pronto ocurriría.

(20) LA UNION MERCANTIL, 9 de Junio de 1891, pág. 1. 
-Era un día de fiesta: en los alrededores del restaurant bullía apiñada multitud, y la plazoleta que le servía de entrada, poblada de mesas y convertida a todas horas en curioso mentidero, hallábase invadida por numerosos grupos de consumidores, formados por notabilidades locales en la política, en el foro, en las letras, en la banca, en todo.21. Así recordaría desde la cárcel Francisco de Asís García Peláez aquel 7 de junio. En ese mismo relato retrospectivo, el periodista refiere su encuentro con Loring, y como éste le instó a salir a la calle, a lo que accedió totalmente confiado.

Después de preguntarle acerca de los artículos del periódico, Loring que empuñaba una llave inglesa -siempre según el relato del periodistale asestó diversos golpes en la cabeza, que obligaron finalmente a García Peláez, en legítima defensa, a utilizar el revólver que llevaba consigo, y después de un disparo al aire, en medio del forcejeo, le disparó dos veces más, impactando de lleno en el cuerpo del político. ¿Por qué portaba el periodista en ese momento un arma de fuego, que acabó usando? García Peláez nunca responderá públicamente a esta cuestión, ni lo mencionará en sus escritos posteriores. Lo cierto es que aquel hecho incrementaría y agravaría las sospechas hacia el periodista ${ }^{22}$.

La personalidad de la víctima, futuro alcalde de la ciudad, y su parentesco con Francisco Silvela, Ministro de la Gobernación, hizo que muy pronto se conociera en Madrid lo sucedido. El Gobernador Civil interino, señor Barroso, en compañía de Jorge Loring Heredia, hermano del político asesinado, telegrafiaría de inmediato al Ministro, recibiendo la noticia el mismo presidente del Gobierno, el malagueño Cánovas del Castillo, pues al parecer Silvela se encontraba en Aranjuez.

Desde el primer momento se inculpó al periodista como culpable de asesinato. Según los comentarios de la prensa, todas las voces ciudadanas se alzaron en su contra, sin que mediaran otras en su favor, o que trataran al menos de poner en cuestión la verdadera autoría y responsabilidad del crimen. La personalidad del político, perteneciente a una acaudalada y prestigiosa familia de la alta burguesía, la preeminencia de la formación política que encabezaba, que había sido recientemente ratifi-

(21) GARCIA PELAEZ, Francisco de A., LLa noche triste. (1893), en La opinión pública y el indulto al periodista Francisco de Asis García Peláez, op. cit., pág. 9.

(22) Según El AVISADOR MALAGUEÑo del día 9 de Junio de 1891, pág. 2, el arma utilizada por el periodista correspondía a un revólver sistema Bulldog de $12 \mathrm{~mm}$. Por su parte el examen facultativo realizado al político daba el siguiente parte médico: edos heridas de arma de fuego; una en la región abdominal que le interesó la arteria aorta central, y la otra en la región del estómago y una de las ramas del ronco celíaco, ambas mortales de necesidad por hemorragia interna. Poco se dijo, sin embargo, de las cinco heridas que García Peláez había recibido en la cabeza. 
cada en las urnas ${ }^{23}$, así como su íntima relación con Silvela, quien pensaba en Loring como futuro alcalde de la ciudad ${ }^{24}$, se acabaron convirtiendo en razones de peso para evitar indagaciones que pusieran en peligro la credibilidad política de los conservadores y de sus líderes. Piénsese en la importancia que para la estrategia política había adquirido la opinión pública después de las primeras elecciones celebradas por sufragio universal pocos meses atrás, en febrero de ese mismo año.

Loring tenía entonces 38 años, y pertenecía a una de las familias más importantes de la oligarquía local; era el segundo de los hijos del matrimonio formado por Jorge Enrique Loring Oyarzábal y Amalia Heredia Livermore, marqueses de Casa Loring. Había estudiado ingeniería de minas en Aachen-Aquisgrán (Alemania), y estaba casado con Ana Martínez Loring, su prima, con la que tenía 6 hijos, uno de ellos de corta edad²s.

En los días siguientes a la muerte de Loring fueron apareciendo nuevos datos y circunstancias que efacilitaban" la rápida interpretación del caso, y cerraban el cerco en torno a García Peláez:

a) Nuevos testigos anónimos: :Se aseguraba ayer que habían declarado como testigos presenciales dos mujeres que estaban muy cerca del sitio de la ocurrencia ${ }^{26}$.

b) Que el objeto con que habia sido golpeado Garcia Peláez era inofensivo: "Parece comprobado lo que anteanoche se decía de voz pública, esto es, que el señor ${ }^{D}$. Manuel Loring Heredia no llevaba bastón ni armas de ninguna clase, suponiéndose que al ser agredido sacó

(23) Las municipales de Mayo de aquel año habían sido sin embargo unas elecciones especiales, pues como resultado de una maniobra de la Junta del Censo, presidida por el Alcalde Sánchez Pastor, impidiendo a los republicanos presentar su lista de interventores alegando que el plazo para ello había expirado, la Coalición Republicana decide retirarse de las mismas. Esta coalición era la única formación política que podía haber sustraído la mayoría en el municipio a los conservadores, tal como habían demostrado en las generales de Febrero. El resultado sería la abultada victoria del Partido Conservador, que logra 14 de los 25 concejales de la Corporación. Víd. CASTILLO NOGUERA, Amalia; CUADRA QUINTANA, Lourdes; y FUENTES ESTEFANI, $M^{2}$ del Pilar, "Defensa conservadora ante el sufragio universal: Las elecciones de 1891 en Málaga., en las Actas del III Coloquio de Historia de Andalucía, Tomo I, Córdoba 1983, págs. 235-236. Y ARCAS CUBERO, Fernando, El republicanismo malagueño durante la Restauración (1875-1923), Ed. Ayuntamiento de Córdoba, 1985; págs. 141-142.

(24) El nombramiento de los alcaldes se hacía mediante decreto real a propuesta del Ministerio de la Gobernación.

(25) Estos y otros datos biográficos sobre Manuel Loring pueden encontrarse, entre otros, en: A.D.E, Caja 172; LA UNION MERCANTIL, 9 de Junio de 1891, pág. 1; o en SESMERO, Julián, .Plaza del Siglo o de Manuel Loring., en su sección La desconocida Málaga de ayer del periódico SUR del día 5 de Agosto de 1991, pág. 10, donde este periodista rememora también el hecho que aquí tratamos.

(26) LA UNION MERCANTIL, 9 de Junio de 1891, pág. 1, -Más datos sobre el crimen de anteanoche. 
del bolsillo del chaleco para defenderse un pequeño metro de los que usan los ingenieros (...) El metro debe obrar en poder del juzgado y dícese que contenía pequeñas manchas de sangre.27.

c) Presunción de inocencia sólo para Manuel Loring: "Acerca de la actitud del señor Loring las opiniones coinciden en que no debía de llevar el propósito de agredir al señor García Peláez, toda vez que racionalmente no debe suponerse tal intención a quien no lleva un revólver, un estoque, un palo o alguna otra cosa que pueda servir para atacar o defenderse con algunas probabilidades de éxito ${ }^{28}$.

Entre las diez y las doce de la mañana del día 15 de junio se celebraron los funerales de Manuel Loring, asistiendo a la ceremonia numerosas personalidades de la política nacional y municipal, de las finanzas, de la jurisprudencia, profesionales, etc. Entre otros, los Gobernadores Civiles de Córdoba y Málaga, Gobernador Militar, Comisión del Ayuntamiento, Diputados a Cortes, Presidente y Magistrados de la Audiencia, Círculo Liberal, Comité del Partido Conservador, etc ${ }^{29}$.

\section{Las consecuencias}

Un mes más tarde, el 18 de julio, el fiscal de la Audiencia, Eusebio Martín, presentará las conclusiones provisionales del caso; en ellas el representante del Ministerio Fiscal se anticipa al veredicto final que pocos meses más tarde acabaría en pena de reclusión para Francisco de A. García Peláez. Es este su análisis de los hechos:

-Entrando en la relación del hecho afirma en sus conclusiones el señor Fiscal, que García Peláez y Loring se internaron en el callejón inmediato al Café Inglés, yendo el primero con el brazo unido a la cintura del segundo y con la mano derecha junto al bolsillo del pantalón donde guardaba el arma homicida, que disputaron y de pronto García Peláez empujó a Loring, obligándole a entrar en el portal de la casa número 3 , disparándole a continuación un tiro, sin lograr herirle. Añade que se agarraron, forcejeando, recibiendo en esta lucha García Peláez, cinco heridas, en cuya curación se invirtieron ocho días; que ya en la calle le hizo aquel a Loring un segundo disparo a quema-ropa, aplicando quizás el cañón junto a la región abdominal; que esta herida obligó a

(27) Ibíd.

(28) Ibíd.

(29) Delegado de Hacienda, Cámara de Comercio, Academia y Escuela de Bellas Artes, Banco de España, Aduana, Jueces de Instrucción y Municipales, Diputación Provincial, Colegios de Médicos y Abogados, Círculo Malagueño, Círculo Mercantil, Liceo, representantes del Comercio, del Clero, Ingenieros, empleados de Hacienda, de los ferrocarriles, de la prensa... IA UNION MERCANTIL, 16 de Junio de 1891, pág. 1, .La ceremonia de ayer. 
D. Manuel Loring a hacer una flexión, recorriendo con la mano puesta en la herida unos 16 metros; y que a la salida de la calle le hizo el tercer disparo, apuntándole a mansalva, por estar aquel ya vacilando para caer en tierra, ${ }^{30}$

El fiscal calificó el delito de asesinato cualificado por la circunstancia agravante de alevosía, y comprendido en el artículo 418 del Código Penal.31; solicitando para el procesado la pena de .cadena perpetua, con las accesorias de interdicción civil e inhabilitación absoluta perpetua, y para el caso de obtener indulto de la pena principal, diez mil pesetas de indemnización a la viuda, y las costas.32.

Las cosas se habían complicado definitivamente para García Peláez, a quien además no resultaría fácil organizar su defensa. Primero fue su procurador, José Eloy Espigares, quien renuncia a hacerlo; más tarde el abogado Arturo Torres; y por último es Pedro Armasa quien a comienzos de Agosto accede a la defensa ${ }^{33}$. Pese a todo, García Peláez sería condenado a diecisiete años de reclusión por el Tribunal del Jurado de la Audiencia provincial de Málaga, el día 24 de diciembre de $1891^{34}$.

Las consecuencias de la muerte de Loring se acabarían cebando sobre toda la familia de Francisco de Asís. La misma noche del 7 de junio, Manuel García Peláez era también encarcelado; y Luis que trató de regresar inmediatamente de Marmolejo, vendría escoltado por la Guardia Civil desde Córdoba para ingresar también en prisión ${ }^{35}$. Sin embargo, una vez confiscados todos sus bienes, ambos pudieron marchar a Santander junto a Francisco, que ya estaba recluído en Santoña. De allí parece ser que Luis salta temporalmente a Paris, y posteriormente se instalan en Madrid. Entre los bienes confiscados a la familia estaba el diario, que dejó de publicarse para siempre desde ese momento.

Respecto a Joaquín Ferrer y Casanova, la desaparición de Loring no lo convertiría en alcalde, pues su nombre no se barajaba entre los princi-

(30) LA UNION MERCANTIL, 19 de Julio de 1891, pág. 1.

(31) Ibíd.

(32) Ibíd. El fiscal presentaba como pruebas las siguientes: Examen del procesado.- Prueba documental- Pericial, con declaración de los facultativos Criado y León, Ramírez Pérez, Cazorla Gómez, Segura, Vicick, García del Olmo, y Gómez Díaz, y de los arquitectos Avila y Rivera Valentín.- Y Testifical, citando 34 testigos. La relación de éstos aparece en LA UNION MERCANTIL del día 31 de Julio de aquel mismo año, pág. 1. Hay que señalar que esta numerosa cantidad de testigos de distinto tipo parece contradecirse con las informaciones iniciales que hablaban de la práctica ausencia de testigos directos.

(33) LA UNION MERCANTIL, 31 de Julio de 1891 y 1 de Agosto de 1891, págs. 1.

(34) El mundo de los periódicos. Anuario de la prensa española y Estados Hispano-Americanos, Madrid 1898-1899, pág. 1066.

(35) GARCIA PELAEZ, Francisco de A., -La noche triste, op. cit., pág. 12. 
pales para ocupar dicho cargo $^{36}$, sobre todo después de haberse visto envuelto en la campaña periodística del DIARIO MERCANTIL; pero sí lo convertiría en jefe de filas del silvelismo provincial, y concejal de Hácien$\mathrm{da}$ del Ayuntamiento. Por otra parte, y en recuerdo de Loring en el primer aniversario de su fallecimiento, el Ayuntamiento de la ciudad daba su nombre a la plaza en la que había resultado muerto.

Distinto porvenir el de cada uno de estos personajes: el político perdía su vida, el periodista su libertad, y el principal instigador salía temporalmente airoso de aquella situación.

\section{1891-1898: LA CONDENA. LA REPERCUSION NACIONAL DEL CASO}

Desde el primer momento, sus hermanos fueron el principal apoyo moral y jurídico de Francisco de Asís, quienes convirtieron en objetivo de sus vidas la libertad del hermano preso. Desde que se instalan en Santander emprenden la tarea de sensibilizar a la opinión pública y a los medios de comunicación en favor de aquel. Y aunque pronto encontrarán eco a sus deseos, las circunstancias políticas del país, que giraban en torno al turnismo de liberales y conservadores, no siempre eran las más favorables. En los siete años que transcurren hasta el indulto, fue durante los períodos liberales cuando sus gestiones encuentraron mayor apoyo. Difícilmente podía ser de otra manera porque la responsabilidad en la falta de esclarecimiento del caso había recaído sobre un gobierno conservador.

Los años 1893,1895 y 1898 fueron los más significativos y cruciales en el largo peregrinar de los hermanos del periodista malagueño por tratar de devolverle a la libertad, aunque ésta la encontrara en el exilio. 1893 , porque marca el inicio del proceso hacia el indulto, con las primeras súplicas; 1895, porque es el año de la mayor movilización y apoyo social en torno al caso; y 1898, porque será el año de la conmuta de la pena, y por tanto de la libertad en el destierro. Los tres momentos se producen bajo gobiernos liberales.

Desde el interior de la cárcel, Francisco de Asís contribuye en la medida de sus fuerzas y de sus posibilidades a mantener despierto el interés por su caso. En varias ocasiones podrá escribir cartas y algún artículo que logran salir de entre las paredes de la prisión para ser publicados o leídos por personas cercanas a él. Así en 1893 escribe :La

(36) Estos nombres fueron los de Fernando Camino Segundo, Enrique López Palacios, Jorge Loring y Heredia, hermano del fallecido, y Sebastián Souvirón y Torres, quien finalmente resultó ser elegido. CASTILLO NOGUERA, A.; CUADRA QUINTANA, Lourdes; y FUERTE ESTEFANI, $M^{2}$ del Pilar, -Defensa conservadora ante el sufragio universal: Las elecciones municipales de 1891 en Málaga., op. cit., págs. 236-237. 
noche triste ${ }^{37}$; también durante la condena escribe a Narciso Díaz de Escovar, y le envía el siguiente poema, obsesionado siempre por los mismos hechos:

No fui yo quien lo hirió; fue su destino

A influjo de su espiritu turbado

Por su pasión y encono dominàdo

Imprudente cruzóse en mi camino

¿Qué hice yo? No lo se, quizás mi sino

Me hizo instrumento de adverso hado

Si de muerte mi ser amenazado

Y mal herido y ciego abrí ...

Nunca mi mente concebir podía

Que mi mano dejase un hombre inerte

Pero en su ser la muerte presidía

E impulsado sin duda por su suerte

Logró en infausto y memorable dia

Con mi muerte social su propia muerte ${ }^{38}$.

En 1896 los hermanos de Francisco de Asís publicarán en Madrid, en la imprenta de Enrique Jaramillo y Requena, un folleto que llevaba por título La opinión pública y el indulto al periodista D. Francisco de Asís García Peláez $z^{39}$. Este folleto se publicó también en francés e inglés para ser distribuido gratis entre la prensa francesa, inglesa y norteamericana. Consta de 38 densas páginas, en las que en forma de dossier se recopilan las súplicas de indulto y muestras de solidaridad y de apoyo recibidas de todo el país, muy especialmente de la prensa y de los círculos intelectuales y económicos de la capital de España. Gracias a este folleto, que el diario EL PAIS de Madrid había anticipado poco antes en forma de hoja suelta, hemos podido conocer algunos detalles importantes del caso.

En octubre de 1893, Luis García Peláez, residente ya en Madrid, elevará a la Reina Regente, María Cristina, la primera de las numerosas súplicas de indulto que serán solicitadas. En aquella ocasión, el hermano del periodista encarcelado acompañaba una súplica del mismo Tribunal del Jurado que lo había condenado, pidiendo la conmuta de la pena que sufría por la de destierro en atención a sus antecedentes y conducta ejemplar, así como varias solicitudes que apoyaban miles de vecinos de Málaga. Firmaban la súplica del Tribunal del Jurado los señores Nicolás y Adolfo de la Torre Bonifaz, Joaquín Guerrero, Nazario de Sepúlveda,

(37) GARCIA PELAEZ, Francisco de Asís, -La noche triste, op. cit. Artículo republicado en La opinión puiblica y el indulto al periodista Francisco de Asís García Peláez, op. cit.

(38) A.D.E., Caja 166.

(39) Como ya hemos citado, un ejemplar del mismo, correspondiente a la edición española, se conserva en el A.D.E., Caja 166. 
Juan Antúnez, Joaquín Franquelo, Eduardo López de Uralde, Antonio Valderrama y A. de Linares ${ }^{40}$.

Sin embargo, el caso empezará a adquirir resonancia nacional cuando comiencen las primeras adhesiones de los periódicos de Madrid. La incansable labor realizada por los hermanos de Francisco de Asís calará pronto en los periódicos de Santander y posteriormente de Madrid, donde se instalaron para estar más cerca de los centros de decisión política y jurídica. En 1895 , veintidos periódicos madrileños envían una carta al Presidente del Gobierno, Práxedes Mateo Sagasta, en la que se solidarizan con las gestiones que la familia del periodista malagueño estaban llevando a cabo. La importancia de esta carta queda de manifiesto en el prestigio de los periódicos y nombres que la firman: Por EL IMPARCIAL, Rafael Gasset.- Por el HERALDO DE MADRID, Augusto de Figueroa.- Por LA CORRESPONDENCIA DE ESPAÑA, Andrés Mellado.- Por EL LIBERAL, Miguel Moya.- Por EL CORREO, J. Ferreras.- Por EL DIA, José Quesada.- Por EL IDEAL, Emilio Prieto.- Por LA CORRESPONDENCIA MILITAR, Diego Fernández Arias.- Por EL GLOBO, Alfredo Vicenti.- Por LA JUSTIICIA, Nicolás Salmerón y García.- Por EL PUEBLO, Emilio de Arroyo.- Por EL NACIONAL, J. Bores Romero.Por EL DIARIO ESPAÑOL, J. Ortiz de Cantos.- Por EL CORREO MILITAR, Juan Lapoulide.- Por EL EJERCITO ESPAÑOL, L. Giner Aribau.Por EL CORREO ESPAÑOL, Benigno Bolaños.- Por EL MOVIMIENTO CATOLICO, Valentín Gómez.- Por LAS DOMINICALES DEL LIBRE PENSAMIENTO, Fernando Lozano.- Por EL PAIS, Alejandro Lerroux.- Por EL SIGLO, Juan Nido.- Por LA PUBLICIDAD, el Director.- Por LA UNION CATOLICA, Damián Ysern.- Por EL RESERVISTA, A. Rodríguez.- Por LA IBERIA, el Director ${ }^{41}$.

Con los liberales en el poder todo hacía pensar en 1895 que se podrían agilizar los trámites para la conmuta de la pena de Francisco de A. García Peláez. El indulto que se preparaba para la prensa hacía presentir que podía incluir el indulto para el periodista. Y Maura, al frente de Gracia y Justicia, podía ser el artífice. Sin embargo, habrá que esperar todavía algún tiempo más. Mientras tanto, importantes sectores de la opinión pública malagueña, sobre la base de la nueva actitud adoptada por el

(40) La opinión pública y el indulto del periodista Francisco de Asís Garcia Peláez, op. cit., pág. 16. Se daba el caso inusitado en nuestros anales penitenciarios, de que los mismos Jurados que intervinieron en la vista de la causa, millares de vecinos de Málaga, la Prensa española en masa, los más eximios escritores de la nación, y Corporaciones oficiales, como Ayuntamientos y Diputaciones, entre ellas la de Madrid, solicitaran reiteradas veces el indulto del señor García Peláez. El mundo de los periódicos, 18981899, op. cit., pág. 1066.

(41) Ibíd., págs. 18-19. 
Tribunal del Jurado que había dictaminado en el caso Peláez• (denominación empleada entonces por el diario EL PAIS), la prensa de Santander (especialmente EL CANTABRICO), donde estaba el recluso, y la prensa de Madrid, tendrían que insistir aún tres años más hasta que en 1898, después de nuevos cambios de gobierno, el indulto se haga realidad.

Entre tanto la influencia que Silvela ejercía desde su escaño en las Cortes servía para retrasar y obstaculizar el proceso que se había emprendido para conseguir el indulto del periodista malagueño. En la sesión del Congreso de Diputados del día 28 de junio de 1895, el por entonces Ministro de Gracia y Justicia, Romero Robledo, contestaba con un *empieza ahora: a una interpelación parlamentaria del diputado Sol y Ortega sobre la situación en que se encontraba el expediente de indulto del periodista. En realidad, dicho expediente había sido archivado apenas sin tramitar $r^{\text {2 }}$. Ello hizo que diversos periódicos se preguntaran por las verdaderas razones que demoraban la solución del caso.

Sin embargo, el asunto adquiría día a día una mayor difusión, y eran cada vez más los sectores ciudadanos y los periódicos de provincias que se sumaban a la petición de indulto. El 9 de mayo de 1895 lo había hecho el Círculo de la Unión Mercantil e Industrial de Madrid, bajo la presidencia de Federico Ortiz, elevando un escrito con 261 firmas a la Reina Regente; el 20 de junio de ese mismo año, la Cámara oficial de Comercio, Industria y Navegación de Madrid, presidida por Pablo Ruiz de Velasco; también por esos días un numeroso grupo de escritores, académicos y exministros; así como los obreros tipógrafos de Madrid.

Firmaban el escrito de los intelectuales y políticos las siguientes personalidades: Manuel del Palacio, Alfonso Pérez Nieva, José J. Herrero, Gaspar Núñez de Arce, Francisco Florez y García, Federico Balart, Juan Pérez Zúniga, Vital Aza, Miguel Ramos Carrión, Vicente Colora do, José R. Carracido, Jacinto Octavio Picón, Eduardo Sanz Scartín, Antonio Sánchez Moguel, Manuel Tamayo y Baus, Antonio López Muñoz, Emilio Ferrari, Conde de la Viñaza, Manuel Jorreto, José María Alcalde, Angel Stor, Carlos Vieyra de Abreu, Tomás Luceño, Eugenio Sellés, José Echegaray, Ricardo de la Vega, Javier Burgos, Pedro Novo y Colson, Leopoldo Cano,

(42) -Al expresarse así el señor ministro de Gracia y Justicia, ignoraba seguramente que por estos días se hallaba en poder del negociado correspondiente el expediente segundo incoado a favor del Sr. García Peláez, cuyo expediente, detenido en el ministerio cerca de catorce meses, fue archivado casi sin tramitar, pues en él no consta el informe del Consejo de Estado, a cuyo alto cuerpo consultivo no se remitió. El por qué este expediente quedó detenido en el ministerio tantos meses y por qué asimismo no se remitió al Consejo de Estado, es cosa que ignoramos hoy, pero que sometemos a la consideración pública. En La opinión püblica y el indulto al periodista Francisco de Asís García Peláez, op. cit., pág. 33. 
Joaquín Olmedilla, Armandio Palacio Valdés, José Castro y Serrano, José de Roure, Marqués de Valmar, Salvador Rueda, José Jurado de Parra ${ }^{43}$.

La importancia de estas adhesiones del mundo de la economía, de las letras y de la política demostraban a todas luces la trascendencia del caso, que empezaba a convertirse en una asignatura pendiente, detrás de la cual se hallaba no sólo la denuncia de una particular desgracia personal que había podido ser enjuicida con mayor o menor dureza, sino también una actitud profundamente política de los sectores liberales y progresistas de la sociedad española contra las irregularidades de la justicia y contra una determinada actuación judicial y política que había confiscado los bienes a toda una familia, cerrado su periódico, y que había conculcado las más elementales normas de dignidad y respeto a las personas así como su propia libertad social, imponiendo una pena excesiva para un crimen no del todo aclarado, que se deseaba mantener oculto para no perjudicar la imagen y los intereses de una parte de la oligarquía local malagueña (Lorings y Heredias) y de algunos políticos nacionales (Silvela, y por extensión el partido conservador).

En 1896 el expediente incoado a favor de García Peláez sería remitido para informe del Consejo de Estado, resultando favorable. La sección de Gracia y Justicia del Consejo de Estado, constituída por los señores Marqués de Ulagares (presidente), y Conde de Montenegrón, Conde de Pallares y Fermín Hernández Iglesias (senador del Reino), ‘acordaron por unanimidad informar favorablemente el expediente citado, de acuerdo con el informe del negociado del Ministerio de Gracia y Justicia, esto es, considerando de justicia que al periodista D. Francisco de Asís García Peláez le sea conmutada por expatriación el resto de la pena de reclusión que sufre en la actualidad ${ }^{44}$.

No todos los periódicos habían manifestado su solidaridad con el periodista malagueño. Algunos, especialmente los periódicos más adictos al partido conservador mostraron siempre reticiencias. Así ocurría con el diario madrileño LA EPOCA que, tras emitir el Consejo de Estado su informe favorable al indulto, escribía lo siguiente: ‘Lejos de nosotros la idea de agravar la situación de quien se halla extinguiendo una pena, por merecida que sea, y así la consideramos en este caso. Mas nuestra compasión se inclina más a las víctimas que a los delincuentes, y tenemos muy vivo todavía aquel triste espectáculo de la familia desolada, de los hijos del muerto vestidos con el luto de la orfandad, para que podamos asociarnos a las instancias que, movidas por sentimientos que respetamos, hizo en favor del reo gran parte de la prensa. Está aun muy

(43) Ibíd., pág. 32.

(44) Ibíd., pág. 35. 
reciente el delito para que el perdón no agrave las tristezas de la distinguida familia, privada del que fuera su sostén y esperanza, de aquel cumplido caballero que se llamó D. Manuel Loring,“5.

Por su parte, EL PAIS, diario que dirigía Alejandro Lerroux, y uno de los más activos en la defensa del indulto, salió inmediatamente al paso de aquellos comentarios. Estas fueron sus palabras en respuesta a las de LA EPOCA: •Muy respetable será el dolor de la familia Loring, a pesar de vivir con las esplendideces del lujo y contar con el apoyo de grandes y poderosas influencias; pero tan respetable es el dolor de la familia del Sr. García Peláez, que ha visto confiscados sus bienes, que ha sufrido persecuciones infames, que por todas partes encuentra los obstáculos que le pone delante el miserable sentimiento de la venganza. Pero aún fue más explícito y duro el diario de Lerroux atacando directamente a Silvela (aunque lo mantuvo en el anonimato), como responsable de la situación, al mismo tiempo que vaticinaba, sin equivocarse, la posibilidad de que el Gobierno no tuviera en cuenta el informe del Consejo de Estado. «El más alto poder del Estado -escribió EL PAIS- no puede ejercer la hermosa prerrogativa del perdón, porque a ello se oponen los asquerosos odios de un personaje político; el Gobierno quizás desatienda el informe del Consejo de Estado por adular a ese mismo personaje!.46.

Así las cosas, el 24 de diciembre de 1896 , siendo Ministro de Gracia y Justicia el Conde de Tejada de Valdosera, se daba por terminado el expediente de conmuta de la pena al periodista malagueño; sin embargo, el Consejo de Ministros acordaba no aconsejar a la Reina el ejercicio de su prerrogativa en favor de García Peláez ${ }^{47}$.

\section{EL EPILOGO: EL DESTIERRO Y LA MUERTE DE GARCIA PELAEZ}

En 1898, por Real Decreto de Gracia y Justicia de 3 de octubre, se le concede por fin el tan anhelado indulto, conmutándosele la pena de reclusión en Santoña por la de extrañamiento ${ }^{48}$. Una vez libre el periodista marchará a Lisboa, y de allí partirá hacia América.

Con el destierro fuera de España todo hacía suponer que «el caso Peláez: se cerraba definitivamente; no obstante, un nuevo hecho pondría al periodista y a la sociedad una vez más frente a él.

Antes de partir para América, el 27 de diciembre de 1898 publicará García Peláez en Lisboa un manifiesto dirigido al pueblo de Málaga. Había llegado a su conocimiento la noticia del suicidio de Joaquín Ferrer,

(45) Ibíd., pág. 36.

(46) Idem.

(47) Ibíd., pág. 37.

(48) El mundo de los periódicos, 1898-1899, op. cit., pág. 1066. 
motivado por un desfalco en la Caja de Ahorros por valor de 600.000 pesetas del que era autor; aquel hecho ponía de nuevo de actualidad las denuncias que en 1891 él mismo realizara desde las páginas de su diario. El suicidio de Ferrer venía a confirmar la veracidad de aquellas denuncias, pues las irregularidades económicas se remontaban a años atrás. Aunque era tarde porque nunca podría volver a España, creyó que era el momento oportuno para que su memoria fuera resarcida: "Fuí el primero en iniciar aquella tan necesaria como desatendida campaña moralizadora; fuí su víctima, y hoy recabo para mí la gloria de mi iniciativa y el derecho a determinar las responsabilida des." ${ }^{49}$.

Y así hará, pues no sólo volverá a insistir en la figura de Ferrer, sino a acusar otra vez más, con firmeza, a los accionistas y miembros de la Junta de gobierno de la Caja que le apoyaron en 1891. "Pues resulta asombroso -escribe García Peláez- que hoy, al cabo de los años, cuando la catástrofe se ha consumado, aparezcan redentores los delincuentes; los cómplices, acusadores. Sí; porque en esas reuniones que ahora se celebran para dar solución al conflicto; en esas reuniones que con espíritu humanitario y justo convoca el caballeroso D. Cristino Martos, digno y merecidísimo gobernador de Málaga actualmente; en esas reuniones toman asiento y hablan, y proponen y discuten, Blasco Barroso, Ghiara, Bolín, Rein, hombres que firmaron a conciencia aquellas cartas que alentaron a Ferrer en su funesta obra de ocho años, los que hicieron suyos los actos todos del Director de la Caja de Ahorros, los que hoy aparecen tan culpables como él, y que, sin embargo, en cínico alarde de imposibles olvidos, son de los primeros en acumular cargos sobre su desdichada memoria, como acostumbran los delincuentes a arrojar sobre el cómplice muerto la responsabilidad del delito.50.

Pero ya le quedaba poco tiempo de vida; su salud se había deteriorado por los años pasados en el inmundo* penal de Santoña, y su alejamiento de España empezaba a dejar en el olvido aquella lucha que había sostenido durante tanto tiempo por defender su libertad y su dignidad, y que le había servido para mantener vivas la ilusión y la esperanza pese al encierro. Aquella etapa de su vida se cerró con el destierro, pero era su vida misma la que se cerraba definitivamente. García Peláez fallecería en 1899, a los 33 años, en plena travesía de La Habana a Nueva York a bordo del vapor ‘Buenos Aires.51.

(49) GARCIA PELAEZ, Francisco de Asís, Al pueblo de Málaga, op. cit. Un ejemplar se conserva en el A.D.E., Caja 172.

(50) Ibíd.

(51) DIAZ DE ESCOVAR, Narciso, Notas manuscritas: Biografía de Francisco de Asís García Peláez, op. cit. 